\title{
Revisiting the Electronic Structure of Cobalt-Porphyrin Nitrene and Carbene Radicals with NEVPT2-CASSCF Calcula- tions: Doublet versus Quartet Ground States
}

\author{
Nicolaas P. van Leest and Bas de Bruin* \\ Homogeneous, Supramolecular and Bio-Inspired Catalysis Group, van 't Hoff Institute for Molecular Sciences (HIMS), Uni- \\ versity of Amsterdam, Science Park 904, 1098XH Amsterdam, The Netherlands.
}

KEYWORDS: cobalt-porphyrin, carbene, nitrene, radical, spin state, DFT, CASSCF.

\begin{abstract}
Cobalt-porphyrin complexes are established catalysts for carbene and nitrene radical group transfer reactions. The key carbene, mono- and bis-nitrene radical complexes coordinated to [Co(TPP)] (TPP $=$ tetraphenylporphyrin) have previously been investigated with a variety of experimental techniques and supporting (single-reference) DFT calculations that indicated doublet $(S=1 / 2)$ ground states for all three species. In this contribution we revisit their electronic structures with multireference NEVPT2CASSCF calculations to investigate possible multireference contributions to the ground state wavefunctions. The carbene $\left(\left[\mathbf{C o}^{\text {III }}(\mathbf{T P P})\left({ }^{\circ} \mathrm{CHCO}_{2} \mathbf{E t}\right)\right]\right)$ and mono-nitrene ([Co $\left.\left.{ }^{\mathrm{III}}(\mathbf{T P P})\left({ }^{\circ} \mathrm{NNs}\right)\right]\right)$ radical complexes were confirmed to have uncomplicated doublet ground states, although a higher carbene or nitrene radical character and a lower $\mathrm{Co}-C / N$ bond order was found in the NEVPT2CASSCF calculations. Supported by EPR analysis and spin counting, paramagnetic molar susceptibility determination and NEVPT2CASSCF calculations, we report that the cobalt-porphyrin bis-nitrene complex $\left(\left[\mathbf{C o}^{\mathrm{III}}(\mathbf{T P P})\left({ }^{*} \mathbf{N N s}\right)_{2}\right]\right)$ has a quartet $(S=3 / 2)$ spin ground state, with a thermally assessable multireference \& multideterminant 'broken-symmetry' doublet spin excited state. A spin flip on the porphyrin-centered unpaired electron allows for interconversion between the quartet and broken-symmetry doublet spin states, with an approximate 10- and 200-fold higher Boltzmann population of the quartet at room temperature or $10 \mathrm{~K}$, respectively.
\end{abstract}

\section{INTRODUCTION}

The application and mechanistic understanding of radicaltype hypovalent group transfer reactions mediated by earthabundant transition metal catalysts has seen tremendous advances in recent decades. ${ }^{1}$ In this regard, cobalt(II)-porphyrin complexes evolved as excellent catalysts for the transfer of nitrene ('NR) and carbene ('CR'R") moieties to unsaturated bonds, $\mathrm{C}-\mathrm{H}$ bonds and heteroatoms via radical-type mechanisms. ${ }^{1,2}$ Carbene transfer ${ }^{3}$ catalyzed by cobalt(II)-porphyrins thereby gives access to the (enantioselective) formation of a plethora of cyclic ${ }^{4,5,6,7,8,9,10,11,12,13,14}$ and otherwise alkylated ${ }^{15,16}$ products. Similarly, nitrene transfer ${ }^{17}$ enables (enantioselective) synthesis of a variety of heterocyclic ${ }^{18,19,20,21,22,23,24}$ and acyclic $^{25,26,27,28}$ nitrogen containing compounds.

Mechanistic studies in our lab have largely focused on the use of cobalt(II)-tetraphenylporphyrin ([CoII(TPP)]) for the formation, and subsequent reactivity of the carbene and nitrene radical intermediates. While the product forming reactions proceed via stepwise radical-type mechanisms, formation of the carbene and nitrene radical intermediates on cobalt is the key step in these catalytic processes. ${ }^{29,30}$ Specifically, axial approach of an (in situ generated) diazo compound, e.g. ethyl diazoacetate (EDA), onto [Co ${ }^{\text {II }}$ (TPP)] leads to destabilization of the Co-localized $d_{\mathrm{z}^{2}}$ singly occupied molecular orbital (SOMO), resulting in single-electron transfer from cobalt to the forming $\pi^{*}$ bond with the carbene precursor (Scheme 1A and B). This leads to $\mathrm{N}_{2}$ extrusion and single-electron population of the $\pi$ symmetric antibonding $\mathrm{Co}-C$ orbital. The thus formed [Co $\left.{ }^{\text {III }}(\mathbf{T P P})\left({ }^{\bullet} \mathrm{CHCO} 2 \mathrm{Et}\right)\right]$ complex is therefore best described as a 'carbene radical' coordinated to a cobalt(III) center. This complex was characterized by means of mass spectrometry and electron paramagnetic resonance (EPR) spectroscopy, of which the latter (in combination with density functional theory (DFT) calculations) indicated that the terminal 'carbene radical' complex has an electronic doublet $(S=1 / 2)$ ground state and is in equilibrium with an off-cycle 'bridging' isomer wherein the carbene is bridged over cobalt and a pyrrolic nitrogen of the porphyrin. ${ }^{29}$

Related 'nitrene radicals' coordinated to a cobalt(III)porphyrin also react with $\mathrm{C}=\mathrm{C}$ and $\mathrm{C}-\mathrm{H}$ bonds via stepwise radical-type mechanisms, and the exact structural and electronic nature of the 'nitrene radicals' was found to depend on the employed nitrene precursor. ${ }^{31,32}$ Activation of an organic azide (e.g. nosylazide, $\mathrm{NsN}_{3}$ ) leads to $\mathrm{N}_{2}$ extrusion and cobalt(II)-tonitrene single-electron transfer, leading to the formation of a mono-'nitrene radical' coordinated to a cobalt(III)-porphyrin; [Co'III(TPP)('NNs)] (Scheme 1A and B). However, usage of the more oxidizing iminoiodinanes (e.g. PhI=NNs) leads to formation of bis-nitrene radical complexes, wherein a second 'nitrene radical' is formed involving porphyrin ligand-tonitrene substrate single-electron transfer, leaving the oxidized porphyrin ligand in an overall mono-anionic ligand-centered radical state in the resulting $\left[\mathbf{C o}^{\mathrm{III}}\left(\mathbf{T P P}^{*}\right)\left({ }^{\circ} \mathbf{N N s}\right)_{2}\right]$ complex (Scheme 1B). The mono- and bis-nitrene radical species were characterized by EPR, UV-vis, IR, vibrational circular dichroism (VCD) and X-ray absorption spectroscopy (XAS), in combination with high resolution mass spectrometry and DFT calculations. 
Scheme 1. (A) Formation of carbene and mono-nitrene radicals on [Co $\left.{ }^{\mathrm{II}}(\mathrm{TPP})\right]$, (B) previous characterization of $\left[\mathrm{Co}^{\mathrm{III}}(\mathrm{TPP})\left({ }^{\circ} \mathrm{CHCO}_{2} \mathrm{Et}\right)\right],\left[\mathrm{Co}^{\mathrm{III}}(\mathrm{TPP})\left({ }^{\mathrm{NNS}}\right)\right]$ and $\left[\mathrm{Co}^{\mathrm{III}}\left(\mathrm{TPP}^{\cdot}\right)\left({ }^{\mathrm{NNN}}\right)_{2}\right]$ as having a doublet spin state, and $(\mathrm{C})$ the work described in this contribution. Red $(\alpha$, up) and blue $(\beta$, down) arrows indicate the spin of the unpaired electrons.

(A) Carbene or mono-nitrene radical formation on [Co"(TPP)]
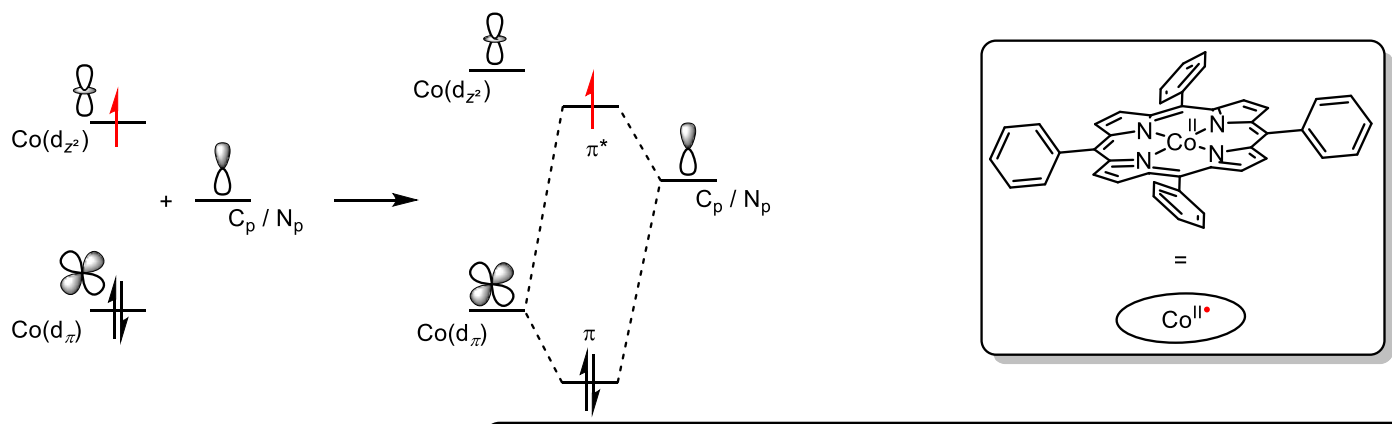

(B) Previous work: doublet ground states
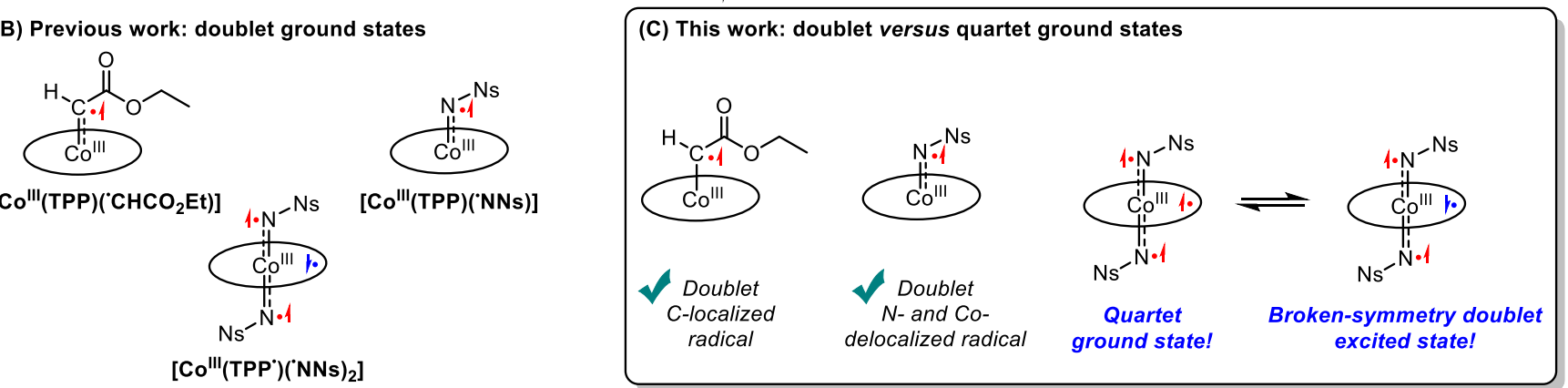

Importantly, EPR and DFT studies indicated that both the mono- and bis-nitrene radical complexes have a doublet $(S=1 / 2)$ spin state. However, DFT is not suitable for the description of complicated broken-symmetry/multireference wavefunctions, ${ }^{33}$ which require post-Hartree-Fock multireference-type calculations such as NEVPT2 ( $N$-electron valence state perturbation theory) corrected CASSCF (complete active space self-consistent field). ${ }^{34,35} \mathrm{We}$ have recently reported the importance of the latter in the correct description of the ground state wavefunction in open-shell cobalt complexes with redox-active ligands. ${ }^{36}$ Therefore, given (i) our interest in cobalt(II)-porphyrin catalyzed carbene and nitrene radical transfer reactions, and (ii) the possible involvement of multireference contributions to the ground state wavefunctions in the key carbene and nitrene radical intermediates, we set out to revisit their electronic structures with NEVPT2-CASSCF calculations.

In this contribution we report that the carbene and mononitrene radical complexes of cobalt-TPP indeed have doublet ground states, which is largely consistent with the DFT calculated electronic structures. The bis-nitrene radical complexes, on the other hand, are now shown to have a quartet ground state with a thermally accessible low-lying multireference ('brokensymmetry') doublet excited state according to NEVPT2CASSCF calculations, EPR analysis and spin counting experiments (Scheme 1C). As this complex has two accessible spin states that are close in energy, we foresee that the insights obtained in this contribution might lead to the application of bisnitrene radical cobalt-porphyrins complexes in two-state reactivity. ${ }^{37}$

\section{RESULTS AND DISCUSSION}

We initiated calculations on the catalytically active terminal carbene radical $\left[\mathrm{Co}^{\mathrm{III}}(\mathbf{T P P})\left({ }^{\circ} \mathbf{C H C O}_{2} \mathbf{E t}\right)\right]$, resulting from reaction between [Co ${ }^{\text {II }}$ (TPP)] and EDA. ${ }^{29}$ Minima on the doublet $\left(S=1 / 2, S^{2}=0.76\right)$ and quartet $\left(S=3 / 2, S^{2}=3.78\right)$ potential energy surface (PES) were located with DFT calculations at the literature benchmarked BP86/def2-TZVP level of theory, ${ }^{29} \mathrm{em}$ ploying an m4 energy grid and Grimme's version 3 ('zero' damping) dispersion corrections on full atomic models (no simplifications). The doublet state was found well below the quartet state $\left(\Delta G^{\circ}{ }_{298 \mathrm{~K}}=-28.2 \mathrm{kcal} \mathrm{mol}^{-1}\right)$, with a spin density distribution of 0.50 on the carbene- $C(C)$ and $0.16 \alpha$-spin excess on Co, according to a ROKS (restricted open-shell Kohn Sham) calculation. The spin density distribution is nearly equal to the SOMO, which is the antibonding combination of the $C_{\mathrm{p}_{y}}$ $(48.8 \%)$ and cobalt- $\mathrm{d}_{y z}(15.9 \%)$ atomic orbitals, leading to an overall Co-C bond order of 1.21. [Co $\left.{ }^{\mathrm{III}}(\mathbf{T P P})\left({ }^{\cdot} \mathbf{C H C O} \mathbf{O}_{2} \mathbf{E t}\right)\right]$ therefore has a $\left(\mathrm{d}_{x y}\right)^{2}\left(\mathrm{~d}_{y z}+C_{\mathrm{p}_{y}}\right)^{2}\left(\mathrm{~d}_{x z}\right)^{2}\left(C_{\mathrm{p}_{y}}-\mathrm{d}_{y z}\right)^{1 \alpha}\left(\mathrm{d}_{z^{2}}-C_{\sigma}\right)^{0}\left(\mathrm{~d}_{x^{2}-y^{2}}\right)^{0}$ electronic structure according to DFT.

Next, NEVPT2-corrected CASSCF $(11,10)$ calculations were performed, employing an active space of 11 electrons in 10 orbitals that describe the bonding and antibonding molecular orbitals between cobalt and the porphyrin $(L)$ or carbene ligand. The doublet state was again found to be more stable than the quartet state $\left(\Delta G^{\circ}{ }_{298 \mathrm{~K}}=-32.3 \mathrm{kcal} \mathrm{mol}^{-1}\right)$, and is comprised of an $83 \%$ main contributor to the total wavefunction. However, 0.76 excess $\alpha$-spin is located on $C\left(0.98\right.$ on the $\mathrm{CHCO}_{2}$ fragment), whereas the spin density on cobalt is negligible $(0.02 \beta$ spin). The contribution of cobalt to the SOMO is reduced to $5.5 \%$ from the $\mathrm{d}_{y z}$ orbital, whereas the $C_{\mathrm{p}_{y}}$ orbital contributes $69.2 \%$ to this molecular orbital (MO), with an overall SOMO localization of $90.4 \%$ on the $\mathrm{CHCO}_{2}$ carbene radical fragment and $5.7 \%$ on Co. A $6 \%$ contribution of a multireference state leads to some population of the $\operatorname{Co}\left(\mathrm{d}_{z^{2}}\right)-\mathrm{C}_{\sigma}$ antibonding orbital from the corresponding bonding combination, somewhat weakening this bond (effective bond order: 0.98). Overall, the electronic structure of $\left[\mathrm{Co}^{\mathrm{III}}(\mathbf{T P P})\left({ }^{\cdot} \mathbf{C H C O} \mathrm{H}_{2} \mathbf{E t}\right)\right]$ is described by $\operatorname{NEVPT2-CASSCF}(11,10)$ as $\left(\mathrm{d}_{x y}\right)^{2}\left(\mathrm{~d}_{x z}\right)^{2}\left(\mathrm{~d}_{y z}\right)^{2}\left(C_{\sigma}+\mathrm{d}_{z^{2}}\right)^{2}\left(C_{\mathrm{p}_{y}}\right)^{1 \alpha}$ $\left(\mathrm{d}_{z^{2}} C_{\sigma}\right)^{0}\left(\mathrm{~d}_{x^{2}-y^{2}}\right)^{0}$ (Figure 1A). 
(A) $\left[\mathrm{Co} "(\mathrm{TPP})\left({ }^{\circ} \mathrm{CHCO}{ }_{2} \mathrm{Et}\right)\right]$

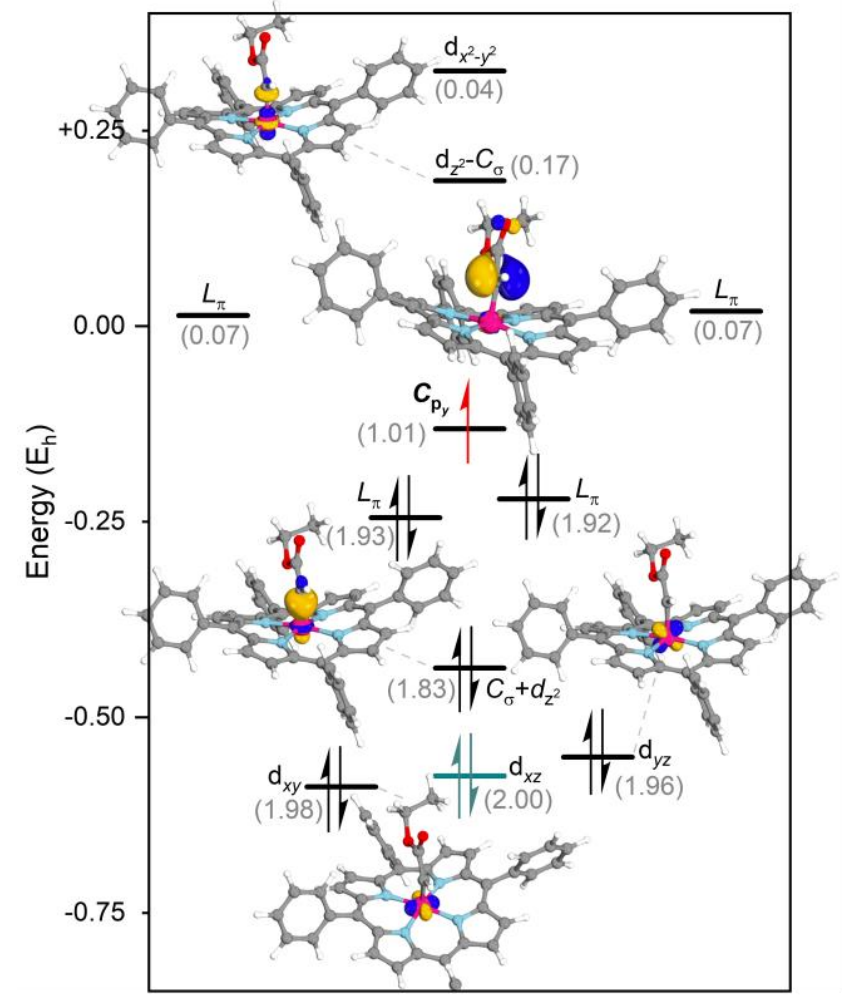

(B) [Co"(TPP)('NNs)]

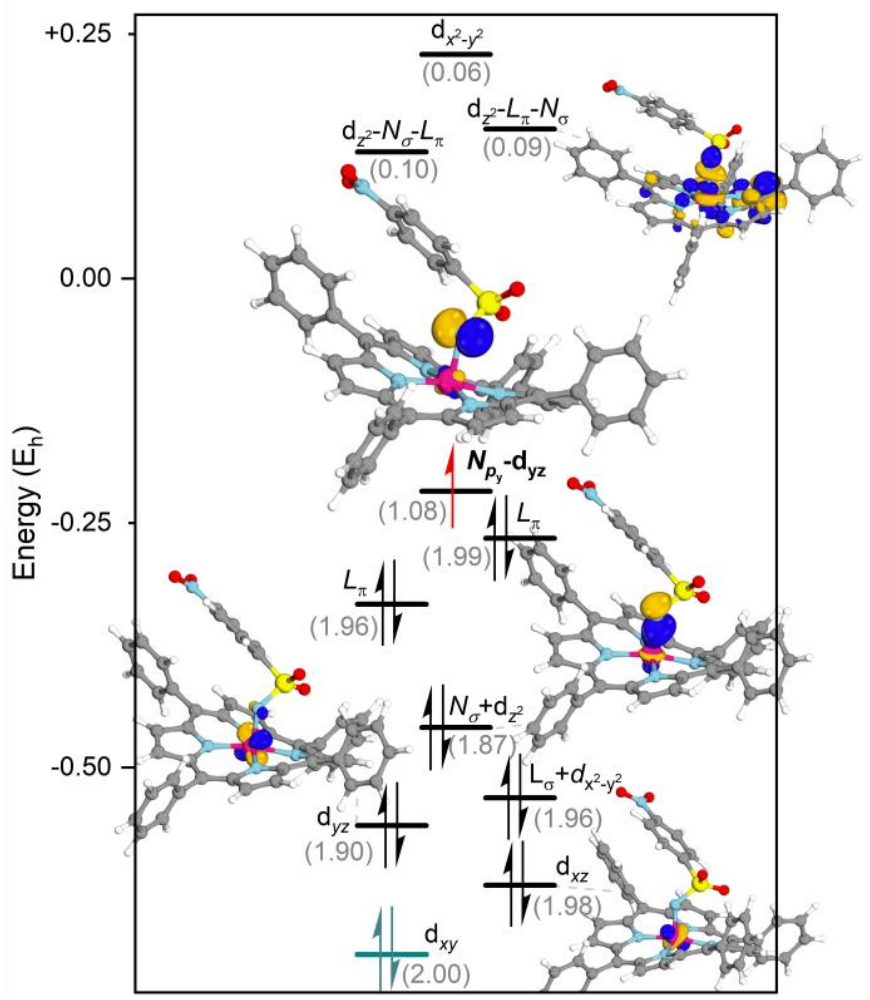

Figure 1. Active spaces, graphical representation of a selection of active orbitals and occupancies in parenthesis from NEVPT2-CASSCF calculations on $\left[\mathbf{C o}^{\mathrm{III}}(\mathbf{T P P})\left({ }^{\circ} \mathbf{C H C O} \mathbf{O}_{2} \mathbf{E t}\right)\right](\mathrm{A})$ and $\left[\mathbf{C o}^{\mathrm{III}}(\mathbf{T P P})\left({ }^{\circ} \mathbf{N N s}\right)\right](\mathrm{B})$ in the doublet state. Isosurface set at $80\left(\mathrm{E}_{\mathrm{h}}<-0.50\right)$ or $70\left(\mathrm{E}_{\mathrm{h}}>\right.$ $-0.50)$. The cyan orbital is uncorrelated and was consequently found in the inactive space. ${ }^{38}$

Whereas the unpaired electron is significantly delocalized over the cobalt-carbene bond according to DFT calculations, $\left[\mathbf{C o}^{\text {IIII }}(\mathbf{T P P})\left({ }^{\cdot} \mathbf{C H C O} 2 \mathbf{E t}\right)\right]$ is thus better described as a pure carbene radical wherein the unpaired $\alpha$-spin electron is almost completely localized on the $C_{\mathrm{p}_{y}}$ orbital according to NEVPT2CASSCF calculations. Although the SOMO has a small contribution from the $\mathrm{d}_{y z}$ orbital, this does not lead to significant spin density on the cobalt(III) center. In addition, the $\mathrm{Co}-C$ bond order is even lower than previously assumed, consistent with the high reactivity of this intermediate.

A similar computational approach was used to investigate the electronic structure of the $N$-nosyl nitrene radical coordinated to a cobalt-TPP platform in [Co $\left.{ }^{\mathrm{III}}(\mathbf{T P P})\left({ }^{\circ} \mathbf{N N s}\right)\right]$. DFT calculations located the doublet $\left(S^{2}=0.76\right)$ as the ground state and the quartet $\left(S^{2}=3.78\right)$ was found at $\Delta G^{\mathrm{o}}{ }_{298 \mathrm{~K}}=+10.9 \mathrm{kcal} \mathrm{mol}^{-1}$. According to a ROKS calculation the SOMO is comprised of an antibonding combination of the nitrene- $N_{\mathrm{p}_{y}}$ orbital $\left(N_{\mathrm{p}_{y}}\right.$, $42.8 \%$ ) and $\mathrm{Co}-\mathrm{d}_{y z}$ orbital (33.8\%), leading to a spin density distribution of 0.43 and 0.34 excess $\alpha$-spin on $N$ and Co, respectively, and a Co-N bond order of 1.39. The DFT calculated electronic structure of $\left[\mathbf{C o}^{\mathrm{III}}(\mathbf{T P P})\left({ }^{\circ} \mathbf{N N s}\right)\right]$ is therefore best described as $\left(\mathrm{d}_{x y}\right)^{2}\left(\mathrm{~d}_{y z}+N_{\mathrm{p}_{y}}\right)^{2}\left(\mathrm{~d}_{x z}+N_{\mathrm{p}_{x}}\right)^{2}\left(N_{\mathrm{p}_{y}}-\mathrm{d}_{y z}\right)^{1 \alpha}\left(\mathrm{d}_{z^{2}}-N_{\sigma}\right)^{0}\left(\mathrm{~d}_{x^{2}-y^{2}}\right)^{0}$.

NEVPT2-CASSCF $(13,10)$ calculations are largely consistent with these results, although the doublet-quartet energy difference is increased to $\Delta G^{\circ}{ }_{298 \mathrm{~K}}=-56.6 \mathrm{kcal} \mathrm{mol}^{-1}$. In the doublet ground state, the electronic wavefunction is dominated by an $86 \%$ main contributor and several states all having coefficients below $3 \%$. The spin density distribution is again consistent with the formation of a nitrene radical, as 0.67 and 0.22 excess $\alpha$ spin is found on $N$ and Co, respectively. The SOMO is comprised of antibonding $N_{\mathrm{p}_{y}}(74.3 \%)$ and cobalt- $\mathrm{d}_{y z}(8.4 \%)$ atomic orbitals, with a total localization of the SOMO on the $\mathrm{NSO}_{2}$ fragment of $82.5 \%$ (Co: 11.9\%). Again, the NEVPT2-CASSCF calculated bond order (1.20) is significantly smaller than predicted by DFT calculations, and the electronic configuration is overall best described as $\left(\mathrm{d}_{x y}\right)^{2}\left(\mathrm{~d}_{x z}\right)^{2}\left(\mathrm{~d}_{y z}\right)^{2}\left(N_{\sigma}+\mathrm{d}_{z^{2}}\right)^{2}\left(N_{\mathrm{p}_{y}}\right.$ $\left.\mathrm{d}_{y z}\right)^{1 \alpha}\left(\mathrm{d}_{z^{2}}-N_{\sigma}-L_{\pi}\right)^{0}\left(\mathrm{~d}_{x^{2}-y^{2}}\right)^{0}$ (Figure 1B).

The situation is more intricate for the bis-nitrene radical complex [Co' ${ }^{\text {III }}\left(\mathbf{T P P}^{*}\right)\left(\mathbf{( N N s}_{2} \mathbf{2}\right.$. DFT analysis of the doublet state afforded an $S^{2}$ value of 1.67 (expectation value 0.75 ), revealing major spin contamination. The DFT solution is a broken-symmetry DFT approximation of the multireference \& multideterminant doublet state that results from the presence of three unpaired electrons with one antiferromagnetically coupled to the other two. This state is captured by DFT as a mixture of the pure doublet and quartet spin states. ${ }^{33}$ Being a single determinant and single-reference method, DFT is not suitable to describe this electronic structure properly, and therefore multireference methods such as NEVPT2-CASSCF ${ }^{34,35}$ are needed for a correct description of the electronic structure of $\left[\mathbf{C o}^{\text {III }}\left(\mathbf{T P P}^{\bullet}\right)\left({ }^{\circ} \mathbf{N N s}\right)_{2}\right]$. 
(A) [Co"(TPP')('NNs) $)_{2}$ : doublet

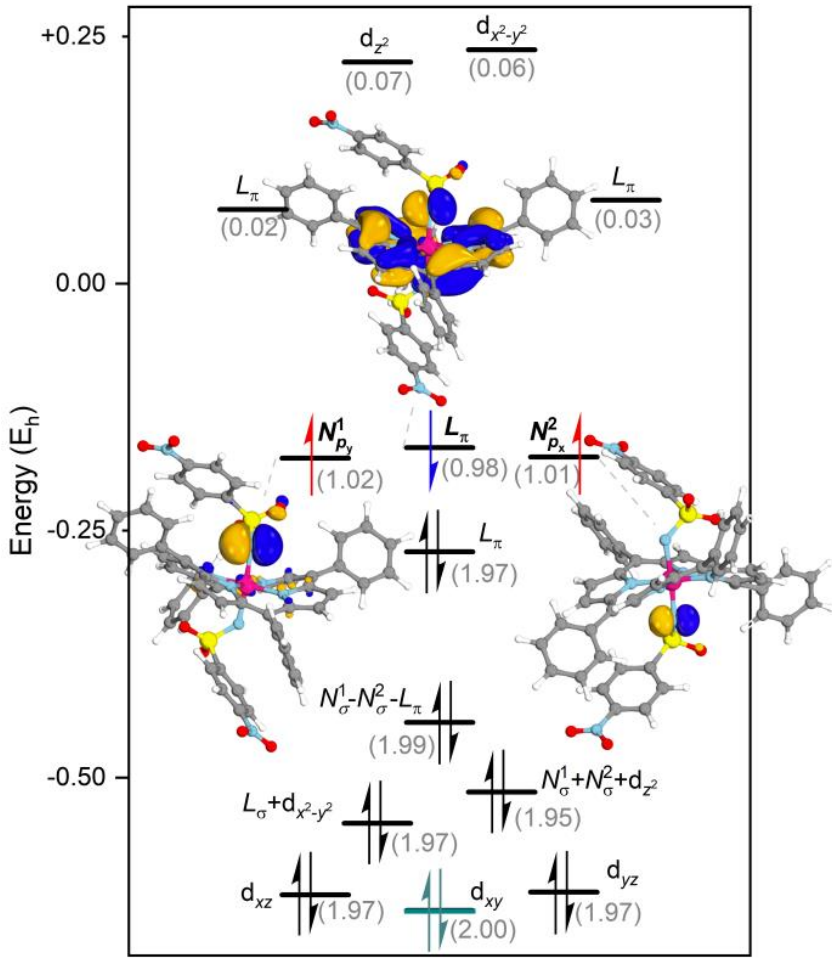

(B) $\left[\mathrm{Co}^{\prime \prime}(\mathrm{TPP})(\mathrm{NNs})_{2}\right]:$ quartet

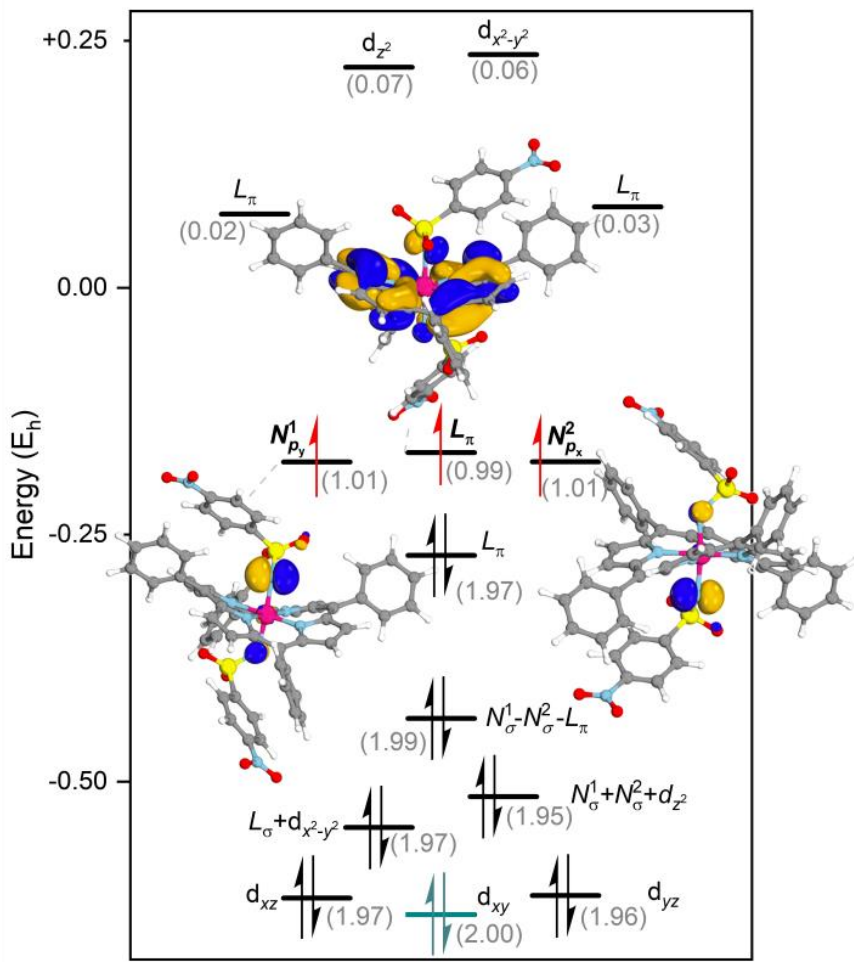

Figure 2. Active spaces, graphical representation of the SOMOs and occupancies in parenthesis from NEVPT2-CASSCF(13,10) calculations

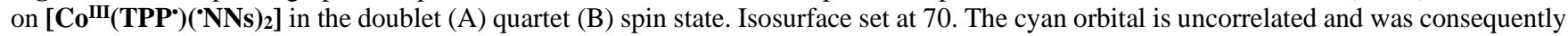
found in the inactive space. ${ }^{38}$

The NEVPT2-CASSCF $(13,10)$ calculations revealed that the quartet state is slightly more stable than the broken-symmetry doublet state $\left(\Delta G^{\circ}{ }_{298 \mathrm{~K}}=-1.4 \mathrm{kcal} \mathrm{mol}^{-1}\right)$. This small energy difference, and the very similar geometrical parameters (see Figure S4 in the Supporting Information) of $\left[\mathbf{C o}^{\mathrm{III}}\left(\mathbf{T P P}^{*}\right)\left({ }^{\circ} \mathbf{N N s}\right)_{2}\right]$ in the doublet and quartet spin states suggest that the complex might have significant Boltzmann population of the brokensymmetry doublet excited state at adequate temperatures. Indeed, EPR spin counting at room temperature revealed that only $\sim 8 \%$ of the total complex concentration resides in the doublet state. ${ }^{31}$ The expectation value for the Boltzmann population of the doublet state is $8.6 \%$ for an energy difference of $1.4 \mathrm{kcal}$ $\mathrm{mol}^{-1}$ at $298 \mathrm{~K}$, which is consistent with the EPR spin counting experiment, suggesting that $91.4 \%$ of the complex resides in the (at room temperature EPR silent) quartet ground state. Determination of the paramagnetic molar susceptibility by Evans' method $^{39}$ afforded $1.51 \times 10^{-3} \mathrm{emu} \mathrm{mol}^{-1}$, which is too high for a pure doublet system (see SI) and therefore also indicates that higher spin states are present.

When the same EPR spin counting experiment was repeated at $10 \mathrm{~K}$ (see Figure S1 in the SI), we found that only $\sim 0.3 \%$ of the total complex concentration resides in the doublet state. Moreover, the quartet ground state is detected at $10 \mathrm{~K}$ as broad resonances in the $0-6000$ Gauss region that are clearly observed upon analysis of the first and double integral of the signal (Figure 3). The broad range of spectral features was well reproduced by the DFT calculated zero-field splitting parameters $(D$ $\left.=0.33 \mathrm{~cm}^{-1}, D / E=0.28\right)$ and $g$ values $(2.005,2.006,2.0125)$ for $\left[\mathbf{C o}^{\text {III }}\left(\mathbf{T P P}^{*}\right)\left({ }^{\circ} \mathbf{N N s}_{2}\right]\right.$ in the quartet state (see Figure S3 in the SI). Moreover, based on the double integrals, $\sim 99.5 \%$ of the total concentration resides in the quartet ground state and only $\sim 0.5 \%$ in the doublet excited state (see SI).

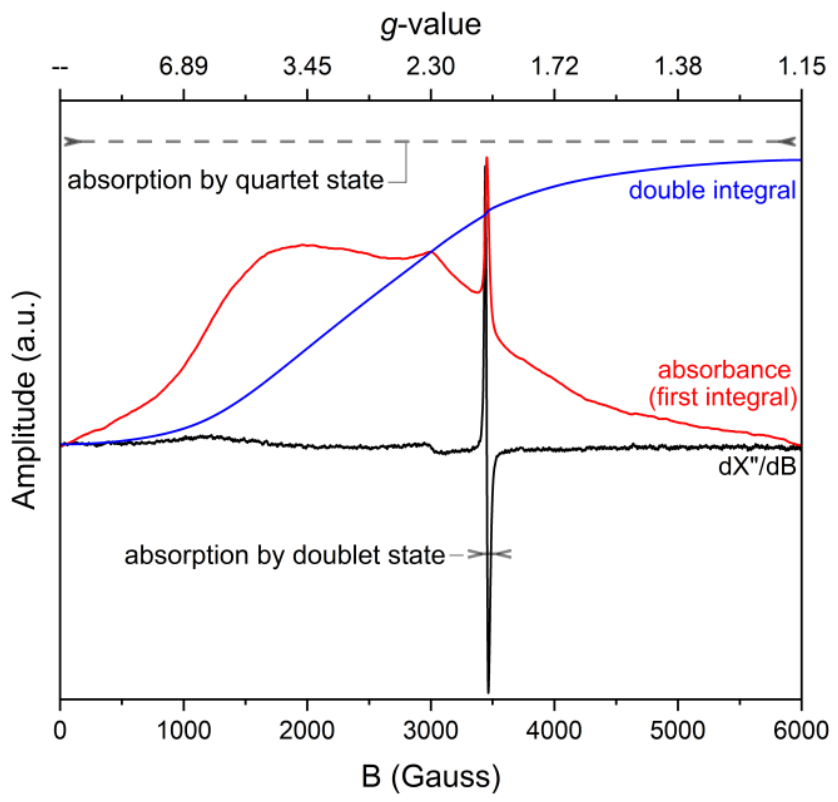

Figure 3. X-band EPR spectrum (black), first integral (red) and double integral (blue) of a $2.425 \mu \mathrm{M}$ solution of [Co $\left.{ }^{\text {III }}\left(\mathbf{T P P}^{*}\right)\left({ }^{\circ} \mathbf{N N s}\right)_{2}\right]$ in $\mathrm{C}_{6} \mathrm{D}_{6}: \mathrm{TBAF}$ at $10 \mathrm{~K}$. The areas of absorbance for the quartet (top) and doublet (bottom) are indicated. Experimental parameters: microwave freq. $9.646369 \mathrm{GHz}$, power $20.00 \mathrm{~mW}$, modulation amplitude $4.000 \mathrm{G}$.

Wavefunction analysis of the NEVPT2-CASSCF $(13,10)$ calculations on [ $\left.\mathbf{C o}^{\text {III }}\left(\mathbf{T P P}^{*}\right)\left({ }^{*} \mathbf{N N s}\right)_{2}\right]$ in the doublet and quartet states are consistent with the formation of two nitrene $\left(N^{1}\right.$ and 
$N^{2}$ ) radicals bearing unpaired electrons of $\alpha$-spin, and an unpaired electron on the porphyrin ligand having $\alpha$ - or $\beta$-spin for the quartet or multireference \& multideterminant 'broken-symmetry' doublet state, respectively (Figure 2). Although these electronic structures are also approximated by DFT calculations, the multireference $\&$ multideterminant wavefunctions obtained from NEVPT2-CASSCF $(13,10)$ calculations are required for the accurate description of the 'broken-symmetry' doublet spin state resulting from the presence of three unpaired electrons.

Specifically, the compositions of the three SOMOs in [Co CoI $\left.\left.^{\text {IITPP' }} \mathbf{(}^{\circ} \mathbf{N N s}\right)_{2}\right]$ in the 'broken-symmetry' doublet state are consistent with the formation of a bis-nitrene radical as the two most stable SOMOs of $\alpha$-spin are respectively $N_{p_{y}}^{1}(63.5 \%)$ and $N_{p_{x}}^{2}(78.1 \%)$ localized (Figure $\left.2 \mathrm{~A}\right)$. The remaining SOMO of $\beta$-spin is mainly ligand centered $\left(L_{\pi}, 73.8 \%\right)$, therefore consistent with the formation of a porphyrin-centered radical that is antiferromagnetically coupled to the two nitrene radicals. In the quartet ground state of [ $\left.\mathbf{C o}^{\text {III }}\left(\mathbf{T P P}^{*}\right)\left({ }^{\circ} \mathbf{N N s}\right)_{2}\right]$, the two most stable SOMOs are also mainly $N_{p_{y}}^{1}(62.2 \%)$ or $N_{p_{x}}^{2}(66.2 \%)$ localized, and the third $\alpha$-spin electron is again mainly found on the ligand $\left(L_{\pi}, 86.2 \%\right)$, but now ferromagnetically coupled to the two nitrene radicals (Figure $2 \mathrm{~B}$ ). The $\mathrm{Co}-N^{1} / N^{2}$ bond orders are both 0.88 , irrespective of the calculated spin state. Overall, the electronic structure of $\left[\mathbf{C o}^{\text {III }}\left(\mathbf{T P P}^{\bullet}\right)\left({ }^{*} \mathbf{N N s}\right)_{2}\right]$ is best described as $\left(\mathrm{d}_{x y}\right)^{2}\left(\mathrm{~d}_{x z}\right)^{2}\left(\mathrm{~d}_{y z}\right)^{2}\left(N_{\sigma}^{1}+N_{\sigma}^{2}+\mathrm{d}_{z^{2}}\right)^{2}\left(N_{\sigma}^{1}-N_{\sigma}^{2}-L_{\pi}\right)^{2}\left(N_{p_{y}}^{1}\right)^{10}$ $\left(N_{p_{x}}^{2}\right)^{1 \alpha}\left(L_{\pi}\right)^{1 \alpha}\left(\mathrm{d}_{z^{2}}\right)^{0}\left(\mathrm{~d}_{x^{2}-y^{2}}\right)^{0}$, with two nitrene radicals on a cobalt(III) center bound to a tetraphenylporphyrin-centered radical (oxidized porphyrin). In the less stable doublet state, a small but significant ( $9.8 \%$ contribution) multireference character is observed between the $N_{p_{y}}^{1}$ and $L_{\pi}$ orbital, causing the latter to accommodate a $\beta$-spin instead of an $\alpha$-spin electron.

\section{CONCLUSIONS}

We have revisited the electronic structures of the catalytically active intermediates in $\left[\mathbf{C o}^{\mathbf{I I}}(\mathbf{T P P})\right]$ catalyzed carbene and nitrene radical transfer; $\left[\mathrm{Co}^{\mathrm{III}}(\mathbf{T P P})\left({ }^{\circ} \mathbf{C H C O}_{2} \mathbf{E t}\right)\right]$, $\left[\mathrm{Co}^{\mathrm{III}}(\mathbf{T P P})\left({ }^{\mathbf{N N N}}\right)\right]$ and $\left[\mathrm{Co}^{\mathrm{III}}\left(\mathbf{T P P}^{*}\right)\left({ }^{\circ} \mathbf{N N s}\right)_{2}\right]$. In continuation of previous studies, we have employed full atomic models in this contribution and compared the wavefunctions as obtained from DFT with those of multireference NEVPT2-CASSCF calculations. We conclude that the doublet ground state electronic structures of $\left[\mathrm{Co}^{\mathrm{III}}(\mathbf{T P P})\left({ }^{\bullet} \mathrm{CHCO} \mathrm{CH}_{2} \mathrm{Et}\right)\right]$ and $\left[\mathrm{Co}^{\mathrm{III}}(\mathrm{TPP})\left({ }^{\mathrm{NNN}}\right)\right]$ are adequately described by DFT calculations in comparison to NEVPT2-CASSCF. However, our new insights suggest that $\left[\mathrm{Co}^{\mathrm{III}}(\mathbf{T P P})\left({ }^{\circ} \mathrm{CHCO}_{2} \mathbf{E t}\right)\right]$ is better described as being a pure carbene radical coordinated to cobalt(III), with a low spin density on cobalt and a smaller contribution $(5.7 \%)$ of cobalt to the SOMO than predicted by DFT. The contribution of cobalt to the unpaired electron density (0.22) and SOMO (11.9\%) is somewhat larger in [Co ${ }^{\text {III }}$ (TPP)( $\left.\mathbf{N N s}\right)$ ], overall resulting in a higher bond order for the mono-nitrene radical (1.20) in comparison to the carbene radical (0.98) coordinated to [Co'III (TPP)].

EPR analysis and spin counting, paramagnetic molar susceptibility determination and NEVPT2-CASSCF calculations are all in agreement, and point to a spin quartet $(S=3 / 2)$ ground state of $\left[\mathbf{C o}^{\text {III }}\left(\mathbf{T P P}^{\circ}\right)\left({ }^{-} \mathbf{N N s}\right)_{2}\right]$, with the multireference $\&$ multideterminant 'broken-symmetry' doublet state being thermally accessible. The electronic structure of the bis-nitrene radicals coordinated to cobalt(III) and a tetraphenylporphyrin-centered radical allows for interconversion between the quartet and 'broken-symmetry' doublet states via a ligand-centered spin flip.

Concludingly, we would like to emphasize the importance of considering the quartet ground state and accessible doublet excited state in future (mechanistic) studies of bis-nitrene radical species on [Co III $\left.^{\text {(TPP }} \mathbf{T P}^{*}\right)$. This might lead to additional mechanistic insight, and possibly the application of thermal- or photoexcitation of the quartet to doublet state, potentially uncovering two-state reactivity in reactions involving these bis-nitrene species.

\section{ASSOCIATED CONTENT}

Supporting Information. Experimental details, EPR and paramagnetic molar susceptibility studies, geometries (xyz coordinates) and energies of stationary points (DFT) and description of the NEVPT2-CASSCF calculations.

\section{AUTHOR INFORMATION}

\section{Corresponding Author}

*Prof. Dr. B. de Bruin. E-mail: b.debruin@uva.nl

\section{Funding Sources}

NWO TOP-Grant 716.015.001 to BdB.

\section{Notes}

The authors declare no competing financial interest.

\section{ACKNOWLEDGMENT}

Financial support from The Netherlands Organization for Scientific Research (NWO TOP-Grant 716.015.001) to BdB is gratefully acknowledged. 


\section{REFERENCES}

(1) van Leest, N. P.; Epping, R. F. J.; van Vliet, K. M.; Lankelma, M.; van den Heuvel, E.; Heijtbrink, N.; Broersen R.; de Bruin, B. In Advances in Organometallic Chemistry; Pérez, P. J.; Stone, F. G. A.; West, R., Eds.; Elsevier, 2018; Vol. 70, pp 71-180.

(2) Lu, H.; Zhang, X. P. Catalytic C-H functionalization by metalloporphyrins: recent developments and future directions. Chem. Soc. Rev. 2011, 40, 1899-1909.

(3) Selected overviews: (a) Dzik, W. I.; Zhang, X. P.; de Bruin, B. Redox Noninnocence of Carbene Ligands: Carbene Radicals in (Catalytic) C-C Bond Formation. Inorg. Chem. 2011, 50, 9896-9903. (b) te Grotenhuis, C.; de Bruin, B. Radical-type Reactions Controlled by Cobalt: From Carbene Radical Reactivity to the Catalytic Intermediacy of Reactive $o$-Quinodimethanes. Synlett 2018, 29, 2238-2250. (c) Intrieri, D.; Caselli, A.; Gallo, E. Cyclopropanation Reactions Mediated by Group 9 Metal Porphyrin Complexes. Eur. J. Inorg. Chem. 2011, 5071-5081. (d) Intrieri, D.; Carminati, D. M.; Gallo, M. The ligand influence in stereoselective carbene transfer reactions promoted by chiral metal porphyrin catalysts. Dalton Trans. 2016, 45, 15746-15761.

(4) Cyclopropanes: (a) Penoni, A.; Wanke, R.; Tollari, S.; Gallo, E.; Musella, D.; Ragaini, F.; Demartin, F.; Cenini, S. Cyclopropanation of Olefins with Diazoalkanes, Catalyzed by $\mathrm{Co}^{\mathrm{II}}$ (porphyrin) Complexes A Synthetic and Mechanistic Investigation and the Molecular Structure of $\mathrm{Co}^{\mathrm{III}}(\mathrm{TPP})\left(\mathrm{CH}_{2} \mathrm{CO}_{2} \mathrm{Et}\right)(\mathrm{TPP}=$ dianion of meso-Tetraphenylporphyrin). Eur. J. Inorg. Chem. 2003, 1452-1460. (b) Fantauzzi, S.; Gallo, E.; Rose, E.; Raoul, N.; Caselli, A.; Issa, S.; Ragaini, F.; Cenini, S. Asymmetric Cyclopropanation of Olefins Catalyzed by Chiral Cobalt(II)-Binaphthyl Porphyrins. Organometallics 2008, 27, 6143-6151. (c) Huang, L.; Chen, Y.; Gao, G.-Y.; Zhang, X. P. Diastereoselective and Enantioselective Cyclopropanation of Alkenes Catalyzed by Cobalt Porphyrins. J. Org. Chem. 2003, 68, 8179-8184. (d) Otte, M.; Kuijpers, P. F.; Troeppner, O.; Ivanović-Burmazović, I.; Reek, J. N. H.; de Bruin, B. Encapsulated Cobalt-Porphyrin as a Catalyst for Size-Selective Radical-type Cyclopropanation Reactions. Chem. Eur. J. 2014, 20, 4880-4884. (e) Ruppel, J. V.; Cui, X.; Xu, X.; Zhang, X. P. Stereoselective intramolecular cyclopropanation of $\alpha$-diazoacetates via $\mathrm{Co}(\mathrm{II})$ based metalloradical catalysis. Org. Chem. Front. 2014, 1. 515-520. (f) Wang, Y.; Wen, X.; Cui, X.; Wojtas, L.; Zhang, X. P. Asymmetric Radical Cyclopropanation of Alkenes with In Situ-Generated DonorSubstituted Diazo Reagents via Co(II)-Based Metalloradical Catalysis. J. Am. Chem. Soc. 2017, 139, 1049-1052. (g) Xu, X.; Lu, H.; Ruppel, J. V.; Cui, X.; Lopez de Mesa, S.; Wojtas, L.; Zhang, X. P. Highly Asymmetric Intramolecular Cyclopropanation of Acceptor-Substituted Diazoacetates by Co(II)-Based Metalloradical Catalysis: Iterative Approach for Development of New-Generation Catalysts. J. Am. Chem. Soc. 2011, 133, 15292-15295.

(5) Cyclopropenes: Cui, X.; Xu, X.; Lu, H.; Zhu, S.; Wojtas, L.; Zhang, X. P. Enantioselective Cyclopropenation of Alkynes with Acceptor/Acceptor-Substituted Diazo Reagents via Co(II)-Based Metalloradical Catalysis. J. Am. Chem. Soc. 2011, 133, 3304-3307.

(6) $2 H$-chromenes: (a) Paul, N. D.; Mandal, S.; Otte, M.; Cui, X.; Zhang, X. P.; de Bruin, B. Metalloradical Approach to 2H-Chromenes. J. Am. Chem. Soc. 2014, 136, 1090-1096. (b) Majumdar, N.; Paul, N. D.; Mandal, S.; de Bruin, B.; Wulff, W. D. Catalytic Synthetis of $2 \mathrm{H}-$ Chromenes. ACS Catal. 2015, 5, 2329-2366.

(7) Furans: Cui, X.; Xu, X.; Wojtas, L.; Kim, M. M.; Zhang, X. P. Regioselective Synthesis of Multisubstituted Furans via Metalloradical Cyclization of Alkynes with $\alpha$-Diazocarbonyls: Construction of Functionalized $\alpha$-Oligofurans. J. Am. Chem. Soc. 2012, 134, 19981-19984.

(8) Phenylindolizines: Roy, S.; Das, S. K.; Chattopadhyay, B. Cobalt(II)-based Metalloradical Activation of 2-(Diazomethyl)-pyridines for Radical Transannulation and Cyclopropanation. Angew. Chem. Int. Ed. 2018, 57, 2238-2243.

(9) 1,2-Dihydronaphthalenes and $E$-aryl-dienes: te Grotenhuis, C.; Das, B. G.; Kuijpers, P. F.; Hageman, W.; Trouwborst, M.; de Bruin, B. Catalytic 1,2-dihydronaphthalene and E-aryl-diene synthesis via $\mathrm{Co}^{\mathrm{III}}$ Carbene radical and $o$-quinodimethane intermediates. Chem. Sci. 2017, 8, 8221-8230.

(10) Pibenzocyclooctenes: te Grotenhuis, C.; van den Heuvel, N.; van der Vlugt, J. I.; de Bruin, B. Catalytic Dibenzocyclooctene
Synthesis via Cobalt(III)-Carbene Radical and ortho-Quinodimethane Intermediates. Angew. Chem. Int. Ed. 2018, 57, 140-145.

(11) Piperidines: Lankelma, M.; Olivares, A. M.; de Bruin, B. [Co(TPP)]-Catalyzed Formation of Substituted Piperidines. Chem. Eur. J. 2019, 25, 5658-5663.

(12) Monobenzocyclooctadiene and dibenzocyclooctenes: Zhou, M.; Lankelma, M.; van der Vlugt, de Bruin, B. Catalytic Synthesis of 8-Membered Ring Compounds via Cobalt(III)-Carbene Radicals. Angew. Chem. Int. Ed. 2020, 59, 11073-11079.

(13) Indoles: (a) Karns, A. S.; Goswami, M.; de Bruin, B. Catalytic Synthesis of Indolines by Hydrogen Atom Transfer to Cobalt(III)Carbene Radicals. Chem. Eur. J. 2018, 24, 5253-5258. (b) Wen, X.; Wang, Y.; Zhang, X. P. Enantioselective radical process for synthesis of chiral indolines by metalloradical alkylation of diverse $\mathrm{C}\left(s p^{3}\right)-\mathrm{H}$ bonds. Chem. Sci. 2018, 9, 5082-5086.

(14) 5-Membered heterocycles: (a) Cui, X.; Xu, X.; Jin, L.-M.; Wojtas, L.; Zhang, X. P. Stereoselective radical C-H alkylation with acceptor/acceptor-substituted diazo reagents via $\mathrm{Co}$ (II)-based metalloradical catalysis. Chem. Sci. 2015, 6, 1219-1224. (b) Wang, Y.; Wen, X.; Cui, X.; Zhang, X. P. Enantioselective Radical Cyclization for Construction of 5-Membered Ring Structures by Metalloradical C-H Alkylation. J. Am. Chem. Soc. 2018, 140, 4792-4796.

(15) Ketenes: Paul, N. D.; Chirila, A.; Lu, H.; Zhang, X. P.; de Bruin, B. Carbene Radicals in Cobalt(II)-Porphyrin-Catalysed Carbene Carbonylation Reactions; A Catalytic Approach to Ketenes. Chem. Eur. J. 2013, 19, 12953-12958.

(16) Alkenes: Lee, M.-Y.; Chen, Y.; Zhang, X. P. General and Selective Olefination of Aldehydes and Ketones Catalyzed by a Cobalt(II) Porphyrin Complex. Organometallics 2003, 22, 4905-4909.

(17) (a) Kuijpers, P. F.; van der Vlugt, J. I.; Schneider, S.; de Bruin, B. Nitrene Radical Intermediates in Catalytic Synthesis. Chem. Eur. J. 2017, 23, 13819-13829. (b) Fantauzzi, S.; Caselli, A.; Gallo, E. Nitrene transfer reactions mediated by metallo-porphyrin complexes. Dalton Trans. 2009, 5434-5443. (c) Intreiri, D.; Zardi, P.; Caselli, A.; Gallo, E. Organic azides: "energetic reagents" for the intermolecular amination of C-H bonds. Chem. Commun. 2014, 50, 11440-11453.

(18) Aziridines: (a) Gao, G.-Y.; Harden, J. D.; Zhang, X. P. CobaltCatalyzed Efficient Aziridination of Alkenes. Org. Lett. 2005, 7, 31913193. (b) Ruppel, J. V.; Jones, J. E.; Huff, C. A.; Kamble, R. M.; Chen, Y.; Zhang, X. P. A Highly Effective Cobalt Catalyst for Olefin Aziridination with Azides: Hydrogen Bonding Guided Catalyst Design. Org. Lett. 2008, 10, 1995-1998. (c) Subbarayan, V.; Ruppel, J. V.; Zhu, S.; Perman, J. A.; Zhang, X. P. Highly asymmetric cobalt-catalyzed aziridination of alkenes with trichloroethoxysulfonyl azide $\left(\mathrm{TcesN}_{3}\right)$. Chem. Commun. 2009, 4266-4268.

(19) Phenoxizinones and benzoxazines: Goswami, M.; Rebreyend, C.; de Bruin, B. Porphyrin Cobalt(III) "Nitrene Radical" Reactivity; Hydrogen Atom Transfer from Ortho-YH Substituents to the Nitrene Moiety of Cobalt-Bound Aryl Nitrene Intermediates $(\mathrm{Y}=\mathrm{O}, \mathrm{NH}) . \mathrm{Mol}$ ecules 2016, 21, 242.

(20) Pyrrolidines: Kuijpers, P. F.; Tiekink, M. J.; Breukelaar, W. B.; Broere, D. L. J.; van Leest, N. P.; van der Vlugt, J. I.; Reek, J. N. H.; de Bruin, B. Cobalt-Porphyrin-Catalysed Intramolecular Ring-Closing C-H Amination of Aliphatic Azides: A Nitrene-Radical Approach to Saturated Heterocycles. Chem. Eur. J. 2017, 23, 7945-7952.

(21) Benzosultams: Ruppel, J. V.; Kamble, R. M.; Zhang, X. P. Cobalt-Catalyzed Intramolecular $\mathrm{C}-\mathrm{H}$ Amination with Arylsulfonyl Azides. Org. Lett. 2007, 9, 4889-4892.

(22) Cyclophosphoramidates: Lu, H.; Tao, J.; Jones, J. E.; Wojtas, L.; Zhang, X. P. Cobalt(II)-Catalyzed Intramolecular C-H Amination with Phosphoryl Azides: Formation of 6- and 7-Membered Cyclophosphoramidates. Org. Lett. 2010, 12, 1248-1251.

(23) Sulfamides and sulfonamides: (a) Lu, H.; Li, C.; Jiang, H.; Lizardi, C. L.; Zhang, X. P. Chemoselective Amination of Propargylic $\mathrm{C}\left(s p^{3}\right)-\mathrm{H}$ Bonds by Cobalt(II)-Based Metalloradical Catalysis. Angew. Chem. Int. Ed. 2014, 53, 7028-7032. (b) Lu, H.; Lang, K.; Jiang, H.; Wojtas, L.; Zhang, X. P. Intramolecular 1,5-C $\left(s p^{3}\right)-\mathrm{H}$ radical amination via $\mathrm{Co}(\mathrm{II})$-based metalloradical catalysis for fivemembered cyclic sulfamides. Chem. Sci. 2016, 7, 6934-6939. (c) Lang, K.; Torker, S.; 
Wojtas, L.; Zhang, X. P. Asymmetric Induction and Enantiodivergence in Catalytic Radical $\mathrm{C}-\mathrm{H}$ Amination via Enantiodifferentiative $\mathrm{H}$ Atom Abstraction and Stereoretentive Radical Substitution. J. Am. Chem. Soc. 2019, 141, 12388-12396. (d) Hu, Y.; Lang, K.; Li, C.; Gill, J. B.; Kim, I.; Lu, H.; Fields, K. B.; Marshall, M.; Cheng, Q.; Cui, X.; Wojtas, L.; Zhang, X. P. Enantioselective Radical Construction of 5-Membered Cyclic Sulfonamides by Metalloradical C-H Amination. J. Am. Chem. Soc. 2019, 141, 18160-18169. (e) Lang, K.; Lu, C.; Kim, I.; Zhang, X. P. Enantioconvergent Amination of Racemic Tertiary C-H Bonds. J. Am. Chem. Soc. 2020, 142, 20902-20911.

(24) Heterocyclic: (a) Jiang, H.; Lang, K.; Lu, H.; Wojtas, L.; Zhang, X. P. Intramolecular Radical Aziridination of Allylic Sulfamoyl Azides by Cobalt(II)-Based Metalloradical Catalysis: Effective Construction of Strained Heterobicyclic Structures. Angew. Chem. Int. Ed. 2016, 55, 11604-11608. (b) Jiang, H.; Lang, K.; Lu, H.; Wojtas, L.; Zhang, X. P. Asymmetric Radical Bicyclization of Allyl Azidoformates via Cobalt(II)-Based Metalloradical Catalysis. J. Am. Chem. Soc. 2017, 139, 9164-9167.

(25) $O$-aminoazobenzenes: Goswami, M.; de Bruin, B. Porphyrin $\mathrm{Co}$ (III)-Nitrene Radical Mediated Pathway for Synthesis of $o$-Aminoazobenzenes. Molecules 2018, 23, 1052.

(26) $\alpha$-Amino Acid Derivatives: Lu, H.; Hu, Y.; Jiang, H.; Wojtas, L.; Zhang, X. P. Stereoselective Radical Amination of Electron-Deficient $\mathrm{C}\left(s p^{3}\right)-\mathrm{H}$ Bonds by Co(II)-Based Metalloradical Catalysis: Direct Synthesis of $\alpha$-Amino Acid Derivatives via $\alpha-\mathrm{C}-\mathrm{H}$ Amination. Org. Lett. 2012, 14, 5158-5161.

(27) 1-3-Diamines: Lu, H.; Jiang, H.; Wojtas, L.; Zhang, X. P. Selective Intramolecular $\mathrm{C}-\mathrm{H}$ Amination through the Metalloradical Activation of Azides: Synthesis of 1,3-Diamines under Neutral and Nonoxidative Conditions. Angew. Chem. Int. Ed. 2010, 49, 10192-10196.

(28) Secondary amines: Jin, L.-M.; Xu, P.; Xie, J.; Zhang, X. P. Enantioselective Intermolecular Radical C-H Amination. J. Am. Chem. Soc. 2020, 142, 20828-20836.

(29) Dzik, W. I.; Xu, X.; Zhang, X. P.; Reek, J. N. H.; de Bruin, B. 'Carbene Radicals' in Co'(por)-Catalyzed Olefin Cyclopropanation. $J$. Am. Chem. Soc. 2010, 132, 10891-10902.

(30) Lu, H.; Szik, W. I.; Xu, X.; Wojtas, L.; de Bruin, B.; Zhang, X. P. Experimental Evidence for Cobalt(III)-Carbene Radicals: Key Intermediates in Cobalt(II)-Based Metalloradical Cyclopropanation. J. Am. Chem. Soc. 2011, 133, 8518-8521.

(31) (a) Olivos Suarex, A. I.; Jiang, H.; Zhang, X. P.; de Bruin, B. The radical mechanism of cobalt(II) porphyrin-catalyzed olefin aziridination and the importance of cooperative H-bonding. Dalton Trans. 2011, 40, 5697-5705. (b) Lyaskovskyy, V.; Olivos Suarez, A. I.; Lu, H.; Jiang, H.; Zhang, X. P.; de Bruin, B. Mechanism of Cobalt(II) Porphyrin-Catalyzed $\mathrm{C}-\mathrm{H}$ Amination with Organic Azides: Radical Nature and H-Atom Abstraction Ability of the Key Cobalt(III)-Nitrene Intermediates. J. Am. Chem. Soc. 2011, 133, 12264-12273. (c) Ragaini, F.; Penoni, A.; Gallo, E.; Tollari, S.; Li Gotti, C.; Lapadula, M.;
Mangioni, E.; Cenini, S. Amination of Benzylic C-H Bonds by Arylazides Catalyzed by Co ${ }^{\text {II }}$-Porphyrin Complexes: A Synthetic and Mechanistic Study. Chem. Eur. J. 2003, 9, 249-259. (d) Caselli, A.; Gallo, E.; Fantauzzi, S.; Morlacchi, S.; Ragaini, F.; Cenini, S. Allylic Amination and Aziridination of Olefins by Aryl Azides Catalyzed by Co ${ }^{\text {II }}(\mathrm{tpp})$ : A Synthetic and Mechanistic Study. Eur. J. Inorg. Chem. 2008, 3009-3019.

(32) Goswami, M.; Lyaskobskyy, V.; Domingos, S. R.; Buma, W. J.; Woutersen, S.; Troeppner, O.; Ivanović-Burmazović, I.; Lu, H.; Cui, X.; Zhang, X. P. Reijerse, E. J.; DeBeer, S.; van Schooneveld, M. M.; Pfaff, F. F.; Ray, K.; de Bruin. B. Characterization of PorphyrinCo(III)- 'Nitrene Radical' Species Relevant in Catalytic Nitrene Transfer Reactions. J. Am. Chem. Soc. 2015, 137, 5468-5479.

(33) Cramer, C. J. Essentials of Computational Chemistry: Theories and Models. 2nd ed; John Wiley \& Sons Ltd: West Sussex UK, 2004; pp 205-210.

(34) (a) Angeli, C.; Cimiraglia, R.; Evangelisti, S.; Leininger, T.; Malrieu, J.-P. Introduction of $n$-electron valence states for multireference perturbation theory. J. Chem. Phys. 2001, 114, 10252-10264. (b) Angeli, C.; Cimiraglia, R.; Malrieu, J.-P. N-electron valence state perturbation theory: a fast implementation of the strongly contracted variant. Chem. Phys. Lett. 2001, 350, 297-305. (c) Angeli, C.; Cimiraglia, R.; Malrieu, J.-P. $n$-electron valence state perturbation theory: A spinless formulation and an efficient implementation of the strongly contracted and of the partially contracted variant. J. Chem. Phys. 2002, $117,9138-9153$.

(35) Olsen, J. The CASSCF Method: A Perspective and Commentary. Int. J. Quantum Chem. 2011, 111, 3267-3272.

(36) (a) van Leest, N. P.; Tepaske, M. A.; Oudsen, J.-P. H.; Venderbosch, B.; Rietdijk, N. R.; Siegler, M. A.; Tromp, M.; van der Vlugt, J. I.; de Bruin. B. Ligand Redox Noninnocence in $\left[\mathrm{Co}^{\mathrm{III}}(\mathrm{TAML})\right]^{0 /-} \mathrm{Com}-$ plexes Affects Nitrene Formation. J. Am. Chem. Soc. 2020, 142, 552 563. (b) van Leest, N. P.; Stroek, W.; Siegler, M. A.; van der Vlugt, J. I.; de Bruin, B. Ligand-Mediated Spin-State Changes in a Cobalt-Dipyrrin-Bisphenol Complex. Inorg. Chem. 2020, 59, 12903-12912.

(37) Dzik, W. J.; Böhmer, W.; de Bruin, B. Multiple Spin-State Scenarios in Organometallic Reactivity. In Spin States in Biochemistry and Inorganic Chemistry; Influence on Structure and Reactivity ( $1^{\text {st }}$ ed.); Swart, M.; Costas, M., Eds.; John Wiley \& Sons, Ltd, 2016, pp 103129.

(38) We attempted to rotate the uncorrelated orbital(s) back in the active space. However, this was unsuccessful. Moreover, inclusion of orbitals with occupancy 2.00 in the active space should be avoided. Aravena, D.; Atanasov, M.; Chilkuri, V. G.; Guo, Y.; Jung, J.; Maganas, D.; Mondal, B.; Schapiro, I.; Sivalingam, K.; Ye, S.; Neese, F. CASSCF Calculations in ORCA: A Tutorial Introduction.

(39) Evans, D. F. The determination of the paramagnetic susceptibility of substances in solution by nuclear magnetic resonance. J. Chem. Soc. 1959, 2003-2005 


\section{For Table of Contents Only}

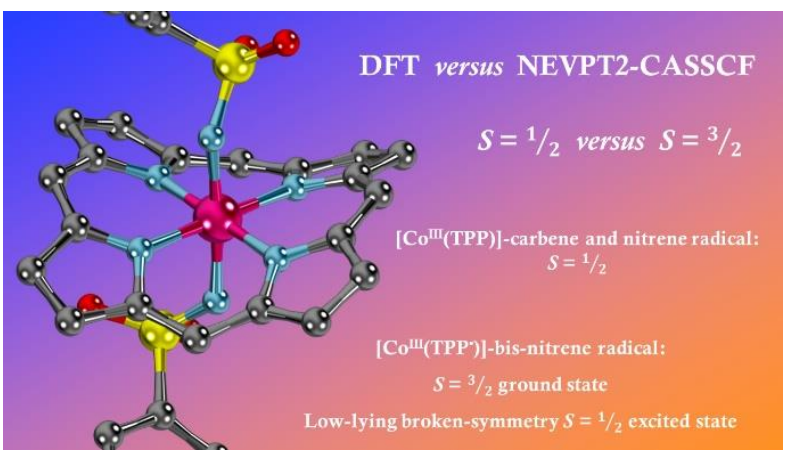

The ground state wavefunctions of cobalt-porphyrin carbene $\left(\left[\mathrm{Co}^{\mathrm{III}}(\mathbf{T P P})\left({ }^{\circ} \mathrm{CHCO}_{2} \mathrm{Et}\right)\right]\right), \quad$ mono-nitrene $\left(\left[\mathrm{Co}^{\mathrm{III}}(\mathbf{T P P})\left({ }^{\circ} \mathrm{NNs}\right)\right]\right)$ and bis-nitrene $\left(\left[\mathrm{Co}^{\mathrm{III}}\left(\mathbf{T P P}^{*}\right)\left({ }^{\circ} \mathrm{NNs}\right)_{2}\right]\right)$ radical complexes were revisited with NEVPT2-CASSCF calculations. The carbene and mono-nitrene radical complexes have doublet ground states, consistent with earlier DFT studies. However, [Co ${ }^{\text {III }}\left(\mathbf{T P P}^{*}\right)\left(\mathbf{( N N s}_{\mathbf{2}}\right.$ ] was found to have a quartet ground state with a thermally accessible multireference $\&$ multideterminant 'broken-symmetry' doublet excited state, according to EPR experiments and NEVPT2-CASSCF calculations. 